\title{
AC 2008-206: ENGINEERING STUDENTS APPLY THEIR SKILLS TO COMMUNITY SERVICE: EFFORTS IN UGANDA, AFRICA
}

\section{Lauri Burke, Colorado School of Mines}

Barbara Moskal, Colorado School of Mines 


\section{Engineering Students Apply Their Skills to Community Service: Efforts in Uganda, Africa}

\section{Abstract}

This paper describes the first semester of scholarship recipient participation in the National Science Foundation Scholarship Program at Colorado School of Mines. This four year program uses international community service to recruit and retain students in mathematics, computer science, and engineering. This program provides undergraduate and graduate students with scholarship support throughout their degree program, mentorship from senior engineering students and faculty, and assistance in mathematics, computer science, and engineering career placement after graduation. Each year of the program, the scholarship recipients complete a real world, multidisciplinary humanitarian engineering project, which provides experience in their field of study. Projects for the academic year 2007-2008 are being completed in collaboration with a non-profit organization, Into Your Hands, and are designed to benefit St. Denis Secondary School in Uganda, Africa. This paper describes the design of the NSF Scholarship program, and the activities and outcomes to date, including benefits to the participating scholarship recipients and to the community served.

Introduction

As a result of the overall decrease in enrollment in engineering and the economic expansion that has resulted from technological advancements, the U.S. is experiencing a shortage of trained mathematicians, computer scientists and engineers, a problem that has persisted for more than a decade. In 1998, the U.S. government responded by increasing the annual number of temporary, professional-worker visas from 65,000 to 115,000 for a three year period in the American Competitiveness and Workforce Improvement Act of $1998^{1}$. The rational behind this Act was to recruit foreign talent in areas of national need. The number of professional-worker visas was increased for another three year period ${ }^{2}$, to 195,000, through the American Competitiveness in the Twenty-First Century Act of 2000. By 2004, it was hoped that the availability of U.S. trained mathematicians, computer scientists and engineers would increase to the level needed to fill the available positions. Since this hope never materialized, a new initiative is underway, the American Competitiveness Initiative of 2006. This initiative dedicates $\$ 136$ billion over ten years to improving education, research, and development in science and engineering in the United States, of which $\$ 5.9$ billion was budgeted for $2007^{3}$. This approach differs from prior efforts in that this Act seeks to increase the pipeline of U.S. trained mathematicians, scientists and engineers. Once students are recruited to these fields, the next step is to retain them until the completion of their degrees.

Concerns have also been raised in the U.S. with regard to the preparation of its students to participate in and contribute to a global community ${ }^{4}$. Toward this goal, the Accreditation Board for Engineering and Technology (ABET) has established accreditation criterion 3h, which states that engineering programs need to provide an education that supports "...the broad education necessary to understand the impact of engineering solutions in a global, economic, environmental, and societal context" (3h). ${ }^{5}$ The United States National Academies, which consist 
of the National Academy of Science, the National Academy of Engineering, the Institute of Medicine and the National Research Council, have predicated that by the year 2020 the world's population will approach 8 billion with the majority of growth occurring in nations that lack an appropriate infrastructure. As a result, difficulties are anticipated in meeting basic human needs, such as water, food, shelter and education, of the people residing in these nations. ${ }^{6}$ Preparing students to respond to global demands is likely to challenge the U.S. higher education system ${ }^{4}$ which has been designed primarily to serve national needs.

This paper describes a program that is funded by the National Science Foundation (NSF) and that seeks to respond to the challenges described here. The NSF Scholarship Program at Colorado School of Mines provides economically burdened undergraduate and graduate students with scholarship support throughout their degree program, mentorship from senior engineering students and faculty, and assistance in mathematics, computer science, and engineering career placement after graduation. Each year of the program, the scholarship recipients complete a real world, multidisciplinary humanitarian engineering project, which provides applications in their field of study. Two projects are currently underway for the academic year 2007-2008 and both are in collaboration with the non-government, non-profit agency, Into Your Hands. Both of these projects address the needs of St. Denis Senior Secondary School which is located near Makando, Masaka District, Uganda. This paper describes the design of the NSF Scholarship program at Colorado School of Mines, how this program has been embedded into the curriculum, and the impact that this project has had on both participating scholarship recipients and St. Denis Senior Secondary School.

\section{Program Description}

The NSF Scholarship Program at Colorado School of Mines provides economically disadvantaged undergraduate and graduate students drawn from the Division of Engineering and the Department of Mathematical and Computer Sciences with mentoring and project experiences that are specifically designed to retain them to the successful conclusion of their degrees. Eleven freshman undergraduates, two master's candidates and two Ph.D. candidates are participating in this program for the academic year 2007-2008. Undergraduate scholarship recipients receive $\$ 5000$ and graduate scholarship recipients receive $\$ 10,000$ in support each year. All scholarship recipients are required to participate in a community service project in their respective area of study under the direction of a research advisor. A major focus of this program is providing scholarship recipients with technical knowledge in mathematics, computer science or engineering through their major course work and applying this knowledge to community service activities while receiving credit toward a Humanitarian Engineering minor. ${ }^{7}$ For the academic year 2007-2008, scholarship recipient teams are completing two community service projects in collaboration with the non-profit organization, Into Your Hands. Both of these projects address the needs of St. Denis Senior Secondary School which is located near Makando, Masaka District, Uganda, and both are described in the sections that follow.

\section{Curriculum Development Project}

Colorado School of Mines's Mathematical and Computer Sciences Department and Engineering Division have been participating in a sequence of grants that are designed to 
improve the instruction that K-12 students receive in mathematics, science and engineering. These grants are funded by the NSF, the Colorado Department of Education, and the Colorado Department of Higher Education. As a result of these efforts, a series of activities have been developed for middle school students and teachers that illustrate the applications of mathematics and science to engineering. The purpose of this project is to convert these activities for on-line delivery in both a regional and international context. Scholarship recipients will use this infrastructure to produce lesson plans that will be tested in a local area school district, and eventually be used in St. Denis Senior Secondary School in Makondo, Masaka District, Uganda. This project requires that scholarship recipients develop a strong background in web development as well as creativity in curriculum design. The Uganda component of this project will further require that the participating scholarship recipients to develop a knowledge and understanding of education in regions beyond their local community.

\section{Water Treatment Project}

Students attending St. Denis Senior Secondary School in Makondo, Masaka District, Uganda, spend their activity break carrying drinking water to the school from a source that is approximately one mile away. This method of providing drinking water to the school is far from efficient and also raises sanitation concerns. As part of this project, scholarship recipients are examining the local region and exploring alternative sources of drinking water. As part of this project, scholarship recipients interact with senior engineering students to determine the benefits and drawbacks of alternative water sources including seasonal streams, borehole or hand dug wells, groundwater run-off cisterns, and rainwater catchments facilities. The facility design takes into account the local hydrogeology, existing power sources, developing a supplementary, renewable power source, and maintenance considerations for different sizes and types of water systems. The scholarship recipients are further expected to consult with an independent organization that will implement the design in Makondo.

\section{Participants}

This section describes the various project participants, including undergraduate and graduate scholarship recipients, Colorado School of Mines faculty, employees of Into Your Hands, and the students and staff at St. Denis Secondary School.

\section{Scholarship Recipients}

Scholarship recipients are divided into two teams: curriculum development team and water treatment team. Both teams are led jointly by a Ph.D. candidate and a Masters' degree candidate. One Ph.D. candidate and one Master's degree candidate are female. Five freshmen undergraduate scholarship recipients are working on the curriculum development project and six freshmen undergraduate scholarship recipients are working on the water treatment project. Only one undergraduate scholarship recipient is female and she is developing engineering curriculum to support the proper usage and maintenance of the water facility installation on the water treatment project. Undergraduate scholarship recipients are expected to dedicate five hours each week throughout the academic year to this project; graduate scholarship recipients are expected to invest ten hours each week. Both of the graduate scholarship recipient leaders of the 
curriculum development project are from the Mathematical and Computer Sciences Department. Both of the graduate scholarship recipient leaders of the water treatment project are from the Engineering Division. None of the undergraduate scholarship recipients have declared a major; however, all have expressed an interest in mathematics, computer science, or engineering.

\section{Colorado School of Mines Faculty}

All of the faculty members contributing to this project have either participated in the development and implementation of the Humanitarian Engineering Program at Colorado School of Mines, an undergraduate minor program specifically designed to provide students the skills necessary to participate in humanitarian efforts, ${ }^{2 \mathrm{G}}$ or the Outreach Scientists Program ${ }^{8}$ a program designed to support K-12 outreach at Colorado School of Mines. Three of the project investigators are male and three are female. Three faculty are from the Mathematical and Computer Sciences Department, two are from the Engineering Division, and one is from the Liberal Arts and International Studies Program. In combination, this investigative team has expertise in mathematics, education, assessment, engineering, water treatment, and curriculum development. Five of the investigators are tenured professors at Colorado School of Mines; one is an instructor.

\section{Into Your Hands}

Into Your Hands is a non-governmental, non-profit organization. The mission of Into Your Hands is "to empower children and families living in rural Uganda to rise above the constraints of poverty and disease through education and enterprise development." $8 \mathrm{~A}$ The NSF Scholarship program works directly with two members of the Into Your Hands agency. One of these individuals is a certified engineer who provides direct support to the project teams. The other member provides first-hand information, as she was raised in a rural community neighboring Makando, Uganda. Into Your Hands acts as a liaison between Colorado School of Mines and the Headmaster of St. Denis, conveying the schools needs and desires as well as raising funds to support the implementation of the project. The role of the scholarship recipients is to develop curriculum and a water facility plan; Into Your Hands will raise the funds and hire the personnel in Kampala to implement these plans.

\section{St. Denis Secondary School}

St. Denis Senior Secondary School is a rural institution located 160 miles southwest of the Ugandan capital city of Kampala, as is illustrated in Figure 1. The school was founded in 1996 and serves approximately 220 male and female students drawn from over 100 surrounding villages. The school supports 16 faculty members and 10 support staff. All instructors at St. Denis Secondary School hold at least a university bachelor's degree. Class sizes are approximately 60 to 80 students. According to the headmaster, the school population is expected to double within the next two years. 


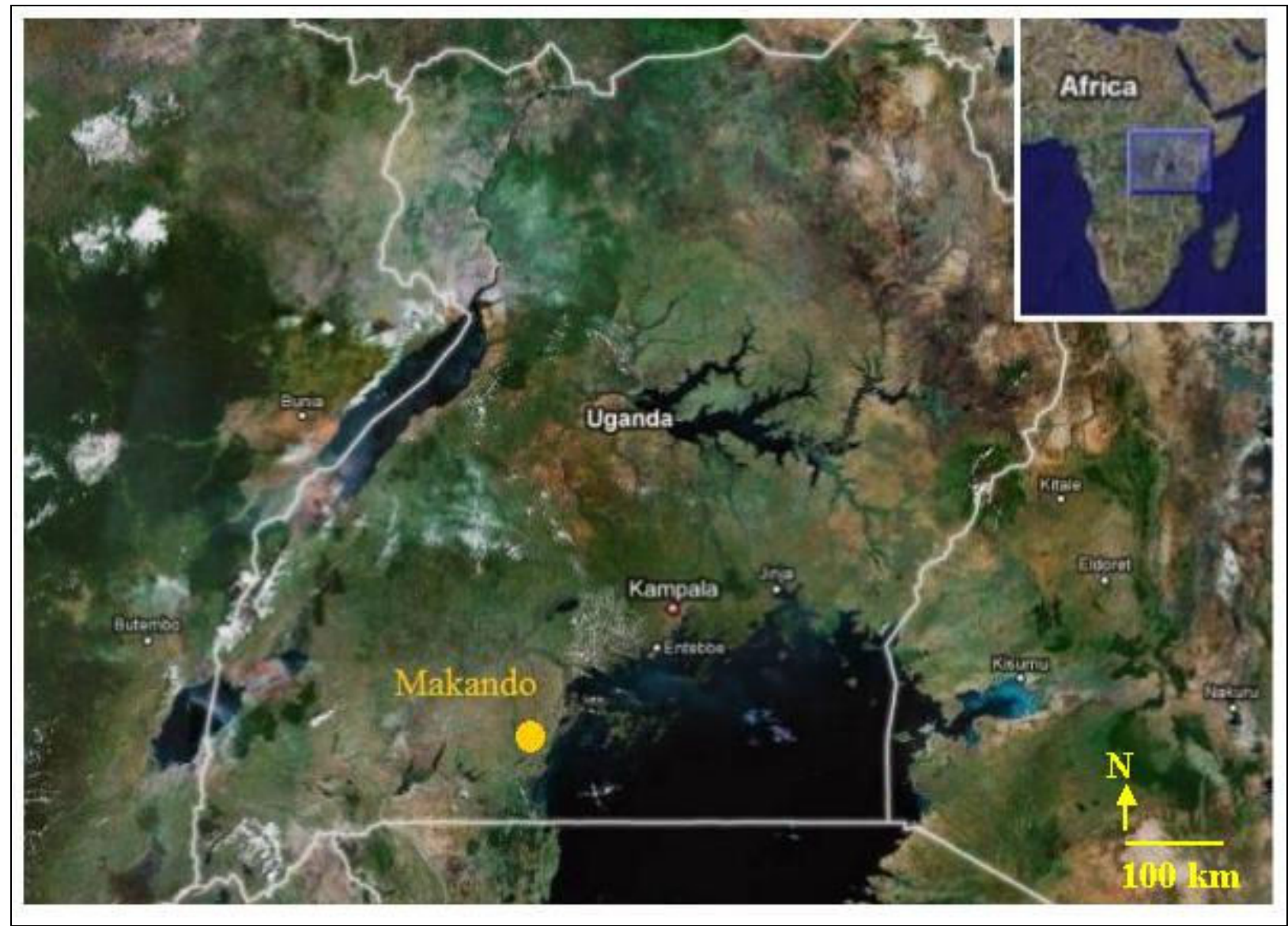

Figure 1. Location map of the rural city of Makando in the Masaka district of Uganda, Africa (courtsey http//maps.google.com). Note: St. Denis Secondary School is located in the bush near Makando.

Education in Uganda is modeled after British 7-4-2 school system in which a student of age seven begins seven years of primary education, progresses to four years of secondary school, and may continue to two years of high school ${ }^{9}$. Secondary school is considered Ordinary level (O-level) education; high school is considered Advanced level (A-level) education. St. Denis is classified as an O-level institution but is beginning to offer several subjects taught at A-level capacity. A student concluding their fourth year of secondary school may select to complete the Ugandan Certificate of Education (UCE) exam. Students who earn an A-level score on the UCE are permitted to continue to high school. Students who successfully complete two years of high school and pass the Ugandan Advanced Certificate of Education (UACEA) are eligible for university education.

Conditions at St. Denis are not ideal. Although unfurnished, dirt-floor dormitories are available for female students, male students sleep where they can, often in the forest. Water is not readily available at the school and must be carried from a non-portable source that is more than one mile away in the wet season. A half day excursion to find drinking water is not uncommon during the dry season. Students receive a single meal each day. The Uganda government mandates that every student receive an updated science and engineering education, but funds are not available to support this mandate. 


\section{Activities}

Funding for this program began in the academic year 2006-2007, during which scholarship recipient recruitment efforts began. Selection of scholarship recipients occurred in the spring of 2007 and participation of selected scholarship recipients in the proposed community service projects began in the fall of 2007. This paper focuses primarily on the outcomes of the first semester of undergraduate and graduate scholarship recipient participation in the fall of 2007.

\section{Selection of Scholarship Recipients}

Scholarship recipient recruitment began in the spring of 2007. At that time, a website was developed which advertised the availability of scholarships and direct mailings were made to entering freshman students who had applied to and had been accepted by the Colorado School of Mines for the fall of 2007. As part of the application process, students were required to submit an application, resume, transcript, and three letters of recommendation. Additionally, students submitted a written statement explaining their career goals and interest in the Humanitarian Engineering program at Colorado School of Mines.

Thirty-five entering freshman, ten of which were female, applied to participate in this program. Twelve were selected. All applications packages were reviewed by six members of our faculty using a common scoring rubric. To the extent possible, names and genders were removed from student applications before the review process began. Twelve undergraduate scholarship recipients were selected to participate in the program and the remaining scholarship recipients were rank ordered on a wait list. Two of the selected scholarship recipients choose not to attend Colorado School of Mines and their scholarships were offered to the next people on the wait list. One scholarship recipient who had accepted the scholarship never arrived on campus. This resulted in the participation of eleven rather than twelve undergraduate scholarship recipients for the fall 2007.

Graduate level recruitment to this program was more difficult. As was done with entering freshman, direct mailings were made to entering students. Only three students applied. One of these applications was incomplete and another did not meet the minimum qualifications. Based on a blind review using a common scoring rubric and completed by members of the faculty, two of the applicants were rejected and one was accepted. A major problem was that graduate student applications appeared to be driven by a lack of funding in the student's research area rather than a desire to participate in this program. Therefore, a different approach was used to recruit the remaining three graduate students. Direct contacts were made with individual departments and divisions with requests for assistance in identifying appropriate, qualified, and interested candidates. This resulted in the selection of three additional graduate scholarship recipients.

\section{Weekly Meetings}

All scholarship recipients were required to attend weekly meetings throughout the semester. During the first meeting, undergraduate scholarship recipients were introduced to the program's director, several members of the investigative team, and the graduate scholarship 
recipient leaders. They further learned of the two proposed projects that were to be completed over the academic year. The four graduate scholarship recipients were assigned to projects based on their background and training, resulting in a doctoral and a master's scholarship recipient from the Mathematical and Computer Science Department leading the curriculum development project, and a doctoral and a master's scholarship recipient from the Engineering Division leading the water treatment program.

Depending on their interests, the undergraduate scholarship recipients volunteered for either the curriculum development or water facility design aspect of the project. One undergraduate from the curriculum development team volunteered to be the web developer for the program and one undergraduate from the water facility team volunteered to develop proper usage and maintenance documentation for the water treatment facility. This division of labor resulted in two teams each led by a doctoral and master's scholarship recipient with five undergraduate scholarship recipients on the curriculum development project, and six undergraduate scholarship recipients on the water treatment project.

Over the first several weeks, the program director guided the undergraduate scholarship recipients in an open-ended exploration designed to provide scholarship recipients with a comprehensive orientation to the political, socioeconomic, historical, cultural, geographical perspective of Uganda. Undergraduates completed research and shared their findings with the group by providing presentations and fact sheets at the weekly meetings. The undergraduates were exposed to library research, presentation delivery, and report writing skills in a context which was aligned with their interests as well as the respective projects.

During the initial six weeks of the program, the graduate scholarship recipients attended separate weekly meetings with the program director for task delegation, resource evaluation, information accumulation, and progress updates. Specifically, the water facility graduate scholarship recipients explored mapping software and computer access options that were available on campus. These scholarship recipients prepared the ArcGIS software, licensing, and accounts in partnership with the campus Geology Department. The curriculum development graduate scholarship recipients familiarized themselves with appropriate materials that had been developed through prior campus efforts ${ }^{12,13}$ and explored how these materials might be altered to match the needs of St. Denis. These materials were available on-line and many of the original developers were available to this project for consultation. As the project advanced, leadership was transferred from the program director to the four graduate team leaders and the program director continued to meet weekly with the graduate team leaders, while the graduate scholarship recipients led the weekly undergraduate meetings. This resulted in cohesive teams with established leadership for the undergraduate scholarship recipients.

The program director was the primary point of contact for Into Your Hands, St. Denis School and the participating faculty members. Members of the board of Into Your Hands were invited to attend campus meetings, which included introductions among participants, discussions of each project's goals, and reviews of each project's progress. Early in the project, e-mail contact was initiated with the headmaster of St. Denis Secondary School who addressed questions concerning the mandated curriculum and the general state of the institution. When needed, the program director solicited the expertise of the other participating faculty members. 


\section{Uganda Site Visit}

In November of 2007, Into Your Hands coordinated student travel to St. Denis for site reconnaissance. The student team met the staff of St. Denis, assessed the educational facilities, obtained water samples for analysis, and collected preliminary geophysical measurements for hydrological exploration. Figure 2 depicts a) Colorado School of Mines students collecting global positioning satellite data to map the buildings within the St. Denis community, b) Colorado School of Mines students obtaining DC resistivity measurements to analyze subsurface conductance indicative of groundwater flow, c) a St. Denis student carrying a jerry can of drinking water, and d) a group photo including the Colorado School of Mines travelers. ${ }^{14}$ This component of the project was funded through the The William and Flora Hewlett Foundation.

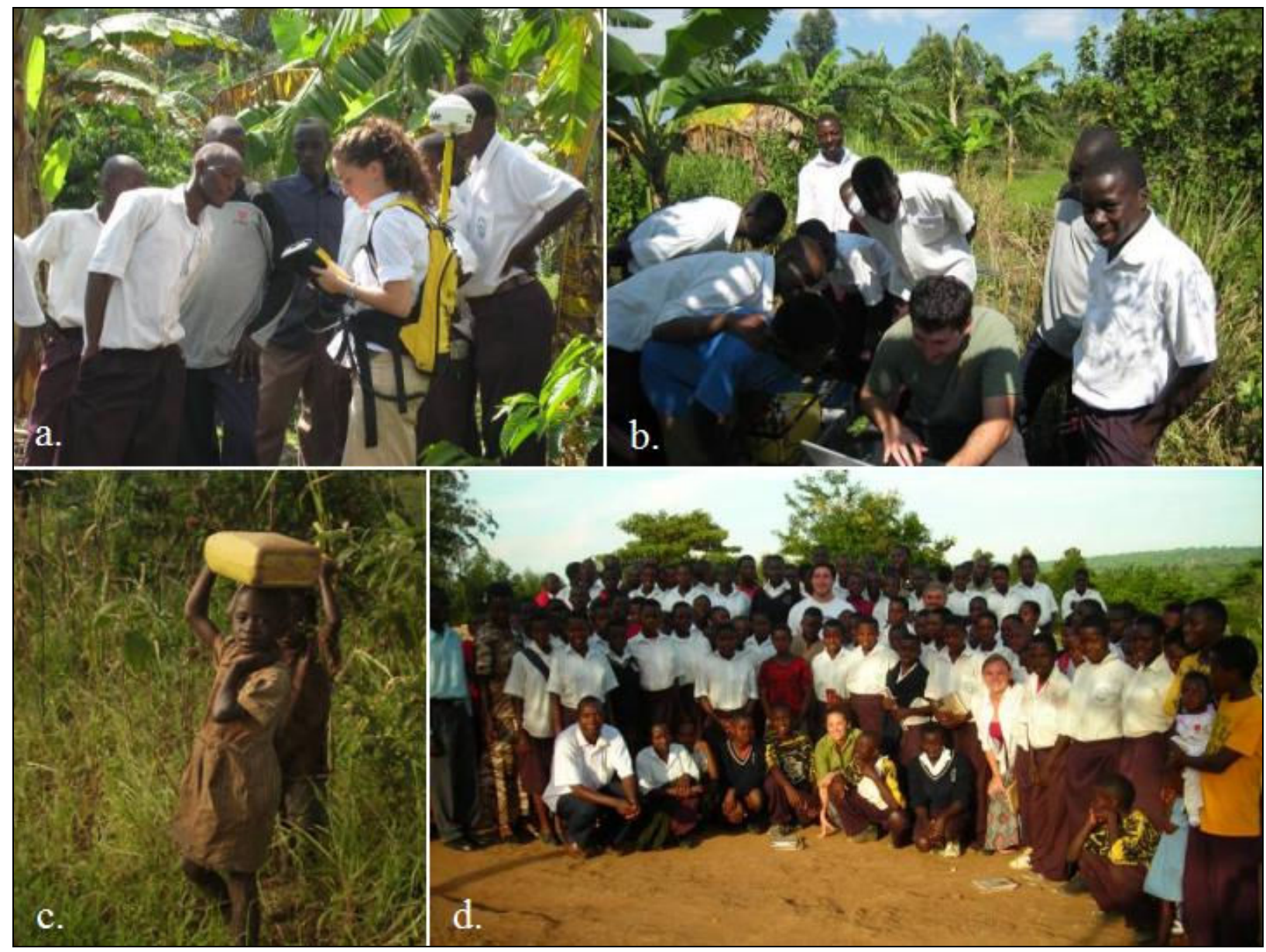

Figure 2. Images of visit to St. Denis (courtesy Munoz et al., 2007).

\section{Outcomes}

The first three outcomes that are discussed here concern scholarship recipients. This includes scholarship recipient retention, first semester grade point averages and their responses to a focus group activity. The two remaining sections describe the outcomes of the scholarship recipients' efforts toward project completion. 


\section{Scholarship Recipient Retention}

As was discussed in the introduction to this paper, one motivator for this program was to improve the retention rate of qualified scholarship recipients at Colorado School of Mines. The average retention rate for first semester freshman at Colorado School of Mines is $83 \%{ }^{14,15}$. For the NSF Scholarship recipients, the retention rate was $100 \%$. None of the scholarship recipients selected to leave the school or the program after their first semester.

\section{Grade Point Average}

Academically, the NSF Scholarship recipients performed well during their first semester. Table 1 summarizes the mean grade point averages (GPA) by degree program for participants during the fall semester of 2007. The GPAs are based on a 4.00 scale. Note that many of the NSF Scholarship recipient freshmen completed accelerated coursework, such as organic chemistry, second semester physics, and/or differential equations. It should be noted further that these results are strongly influenced by the careful screening process that was used in the selection of scholarship recipients. In comparison, the ten eligible and wait-listed scholarship applicants, who had comparable high school GPAs, earned an average 2.59 GPA for the Fall 2007 semester at the Colorado School of Mines. In summary, the participating undergraduate scholarship recipients performed well above their academic peers.

\begin{tabular}{|l|l|}
\hline Degree Program & Grade Point Average \\
\hline Doctoral Candidate & 4.00 \\
\hline Master's Candidate & 3.60 \\
\hline Freshmen Undergraduate & 3.31 \\
\hline
\end{tabular}

Table 1. Fall 2007 grade point averages by degree program for NSF scholarship participants.

\section{Focus Group Responses}

A focus group involving the undergraduate and graduate scholarship recipients was conducted at the end of the fall 2007 semester. The questions that were asked are displayed in Figure 3A. Scholarship recipient responses were examined for common themes, a process known as emergent categories, and categorized based on these themes. Each sentence or phrase which was recorded in the field notes was coded according to these categories. There were 7, 10, 15, 16 , and 17 sentences or phrases recorded by the field recorder with respect to the categories of networking, communication, project logistics, topical research, and global perspective, respectively. Figure 3B provides a definition of the types of comments that were included in each category. 
A. Questions for the focus group discussion:

1. What are the benefits that you have already experienced as a result of participating in this program?

2. What are the drawbacks that you have experienced as a result of participating in this program? How can these be eliminated or minimized?

3. How has participation in this project influenced the friendships and professional relationships that you have developed?

4. How do you feel your participating in this project will influence your future?

5. How has participation in this project influenced you future career aspirations?

6. How has participation in this project influenced your understanding of what it means to be an engineer/mathematician/computer scientists?

7. Additional comments or recommendations?

Figure 3A. Focus Group Questions

B. Focus group responses were categorized based on themes:

Networking - building professional relationships with professors, graduate students, other Scholarship recipients, off campus individuals, non-governmental organizations, industry recruiters, being a member of a supportive peer group, establishing friendships within the program

Communication - interaction with St. Denis Secondary School in Uganda, Africa, contact between the two project groups, communication with the NSF Scholarship Program director

Project Logistics - leadership responsibilities, scheduling meetings via email, facilitating meetings, maintaining timesheets, working in a team environment

Topical Research - building library and internet research skills, appreciation for methodology behind research inquiry, creative approach to real-world problem solving, working with uncertainty and open-ended questions

Global Perspective - broader awareness of living and educational conditions in Sub-Sahara East Africa, the role of American engineers, mathematicians, and scientists in the world, inspiration to pursue humanitarianism in school and career paths

Figure 3B. Focus Group Themes

Several of the graduate level students indicated that during job interviews, industrial recruiters paid particular attention to the student's contributions to this project, possibly providing them with an employment advantage. Many of the undergraduate recipients commented on the strong friendships that they had established as a result of project participation, both with other students and with the faculty. Freshman reported that participation in this project 
provided them with a successful peer group with which to interact from the time that they entered Colorado School of Mines. The freshmen viewed the graduate team leaders as role models, especially in the areas of proper faculty interaction and a broader perspective of coursework and research. The graduate participants found the enthusiasm of the freshmen to be a refreshing and inspirational experience.

A common concern among scholarship recipients was the difficulty of communicating with the headmaster at St. Denis Secondary School. Since the headmaster had to drive three hours to acquire internet access, his responses to inquiries sometimes took weeks. This component of the project provided scholarship recipients with a new perspective on the resources that are available to the global community. The global perspective and international awareness afforded by the project was new territory to virtually every NSF Scholarship recipient. Several scholarship recipients remarked that their participation in the project has inspired them to continue with humanitarian efforts throughout college and into their career.

Participants also learned basic employment skills, such as maintaining a time log, interacting in a team environment, and scheduling meetings via email. Scholarship recipients further commented on the challenges of developing curriculum or of using ArcGIS software, which was required for the water treatment project.

\section{Timesheets}

Scholarship recipients tracked their weekly efforts related to the curriculum development and the water facility design projects. Graduates were required to dedicate ten hours to the NSF Scholarship Program; whereas, undergraduates were required to contribute five hours per week. Table 2 summarizes the efforts of the scholarship recipients during the fall 2007 semester. The reported hours are the mean hours per week across students. Based on this table, the freshmen dedicated a large component of their time to completing library and internet research, as well as interacting with faculty members associated with the NSF Scholarship Program. The graduate students primarily organized their teams, and maintained the accountability of its members.

\begin{tabular}{|l|l|l|l|l|l|l|l|}
\hline $\begin{array}{l}\text { Degree } \\
\text { Program }\end{array}$ & $\begin{array}{l}\text { Total } \\
\text { Average } \\
\text { (hrs) }\end{array}$ & $\begin{array}{l}\text { ArcGIS } \\
\text { Mapping } \\
\text { (hrs) }\end{array}$ & $\begin{array}{l}\text { Curriculum } \\
\text { Development } \\
\text { (hrs) }\end{array}$ & $\begin{array}{l}\text { Research } \\
\text { (hrs) }\end{array}$ & $\begin{array}{l}\text { Weekly } \\
\text { Meetings } \\
\text { (hrs) }\end{array}$ & $\begin{array}{l}\text { Met with } \\
\text { Faculty } \\
\text { (hrs) }\end{array}$ & Other \\
\hline $\begin{array}{l}\text { Doctoral } \\
\text { Candidate }\end{array}$ & 12.6 & 1.3 & 2.9 & 4.9 & 3.5 & 0.9 & 1.3 \\
\hline $\begin{array}{l}\text { Master's } \\
\text { Candidate }\end{array}$ & 12.1 & 6.7 & 2.3 & 2.7 & 2.3 & 0.9 & 1.8 \\
\hline $\begin{array}{l}\text { Freshmen } \\
\text { Undergraduate }\end{array}$ & 7.0 & 2.5 & 1.3 & 3.8 & 1.0 & 2.5 & 0.1 \\
\hline
\end{tabular}

Table 2. Average hours per week per group

Note: Efforts of the scholarship recipient during the Fall 2007 semester is given in average hours per week per student. The Total Average column reflects the average hours worked each week, by degree program, for scholarship recipients working on both of the project teams. The other columns represent the average of the semester total hours for each activity. The reader should not anticipate the total average would equal the sum of the sub-averages, since the sub-averages 
reflect the efforts of two different groups. Graduate and undergraduate students dedicated above and beyond their respective ten and five hours per week requirements.

All eleven freshman exceeded their five hours per week minimum requirement, and the four graduate students consistently met or exceeded their ten hours per week requirement. Initially, the two teams familiarized themselves with the project responsibilities and logistics. The research and development phase of the project required additional efforts, and all team members met those challenges. Weekly efforts by the curriculum development team steadily increased throughout the semester. The water facility design team worked at a consistent level throughout the semester.

\section{Curriculum Development Team}

A subset of the scholarship recipients are seeking to develop curricula that builds students' conceptual understanding of science while reinforcing these concepts through interactive and interdisciplinary laboratory experiments. The laboratory experiments are being adapted from previous efforts at Colorado School of Mines to improve science instruction in the United States at the K-12 level ${ }^{4}$. All of the adapted materials must further be aligned with mandated Ugandan government science curriculum ${ }^{16}$ and utilize resources available in Uganda.

Consistent with the government mandates, Table 3 provides the course sequence that has been proposed by scholarship recipients to St. Denis' headmaster. This sequence is intended to cultivate critical thinking and scientific understanding as well as introduce early the concepts that will have the greatest positive impact on students' lives.

\begin{tabular}{|l|l|l|l|}
\hline & Trimester 1 & Trimester 2 & Trimester 3 \\
\hline Secondary Year 1 & General Science I & General Science II & General Science III \\
\hline Secondary Year 2 & Biology I & Biology II & Agriculture I \\
\hline Secondary Year 3 & Agriculture II & Physics I & Physics II \\
\hline Secondary Year 4 & Chemistry I & Chemistry II & Field Session \\
\hline
\end{tabular}

Table 3. Proposed course sequence for four years of education for St. Denis Secondary School, Uganda.

The proposed curriculum begins with general science which will introduce students to the rigors of scientific observation and theory. Studies in general science will foster an appreciation for the interconnected nature of various areas of science and will include a specific emphasis on geology, geophysics, meteorology, and astronomy. Students will further learn to apply the scientific method and to record scientific data collected from their local environment.

The second year is proposed to begin with an in-depth study of biology. The study of biology is proposed early in the sequence because of the challenges that Uganda is facing with respect to communicable diseases and sanitation concerns. Topics in biodiversity, cellular functions, reproduction, and genetics will provide a foundation for a detailed examination of agricultural sciences, which will be the emphasis of the third trimester of the second year and the first trimester of the third year. The Ugandan government is currently promoting the notion of large-scale, agricultural farming and is encouraging schools to adopt an active role in urban 
development. Exposure to agriculture as an applied science in the second and third year directly contributes to the government's efforts and will allow students to apply their knowledge to family and community improvement projects during their annual academic breaks.

Physics is proposed as the topic of study for the second and third trimester of the third year. In adherence with the government mandate, the physics curriculum will include mechanics, fluid dynamics, electricity, and magnetism. The final area of scientific study is proposed to be chemistry and is scheduled to occur in the first and second trimester of the fourth year. Laboratory experiments in both physics and chemistry are planned such that they will be immediately applicable to the local situation. For example, the experimental technique of distillation, filtration, and evaporation could be applied to water purification, a pressing issue within the community.

The proposed curriculum ends with a Field Session course. This activity is modeled after the senior design course at Colorado School of Mines in which students apply their engineering knowledge to solve real-world problems. In the proposed St. Denis curriculum, Field Session represents a formal course of study and inquiry into a local, community level improvement project. For example, students could investigate the feasibility of developing and implementing a computer laboratory for their school. Each year, the faculty and staff of St. Denis would identify an appropriate community service project that complements the curricula.

Under the guidance of the two graduate team leaders, five freshmen scholarship recipients are working to adapt and develop the proposed curriculum materials for St. Denis. From the subjects defined in Table 3, the freshmen have selected the subjects with which they feel most comfortable. Although each freshman scholarship recipient has a defined area for individual investigation and development, there is a continuous exchange of ideas among the group for improvement purposes. The freshmen have established objectives to address within their respective disciplines and they are in the process of compiling content and concepts. Additionally, they are exploring various laboratory experiments that may be applicable given the limited resources of St. Denis.

\section{Water Facility Design Team}

During an initial brainstorming session, the undergraduate scholarship recipients defined what they needed to know, from an engineering perspective, to complete the proposed project. This resulted in a list of ideas, many of which could be addressed through the availability of ArcGIS maps. Given this, the first activity for this project was to create the necessary maps. Three mapping teams were established with two undergraduate scholarship recipients on each team. These teams conducted informational research and distillation into comprehensive ArcGIS maps under the guidance of their graduate leaders. Although the undergraduate scholarship recipients did not have the necessary background or experience to use ArcGIS software, the graduate leaders did. The ArcGIS software, licenses, and hardware were all provided by the Colorado School of Mines's Geology Department.

A major challenge to these efforts has been the extremely limited electronic data that is available with respect to Uganda. Even when the necessary data is available, it is often not in 
ArcGIS format. To populate the ArcGIS database, numerical database information was downloaded from internet sources. The scholarship recipients then summed the values for each county in Uganda. The numerical data by county was converted into ArcGIS format and imported into the mapping software. Despite these challenges six separate maps were created: 1 ) meteorology, 2) climatology, 3) socioeconomics, 4) population density, 5) watersheds and 6) topography. The final goal is to develop a single map with layered information in ArcGIS format. The maps themselves will be used to determine the expected annual rainfall, evaluate potential locations for a water facility based on local topography and regional watershed geometry, and develop a cultural appreciation through socioeconomic understanding.

Figure 4 provides an example of the ArcGIS mapping efforts that are in progress. This map illustrates the percentage of the population below the poverty line for each political district in Uganda. Data was obtained from internet sources and tabulated by individual county to create the ArcGIS database for this map. ${ }^{17,18}$ From studying this economic distribution map in conjunction with the spatial population distribution map, it is evident that 1) dense populations occur where there are infrastructures, such as roads and cities, and 2) that poverty increases in the rural regions, such as the location of St. Denis.

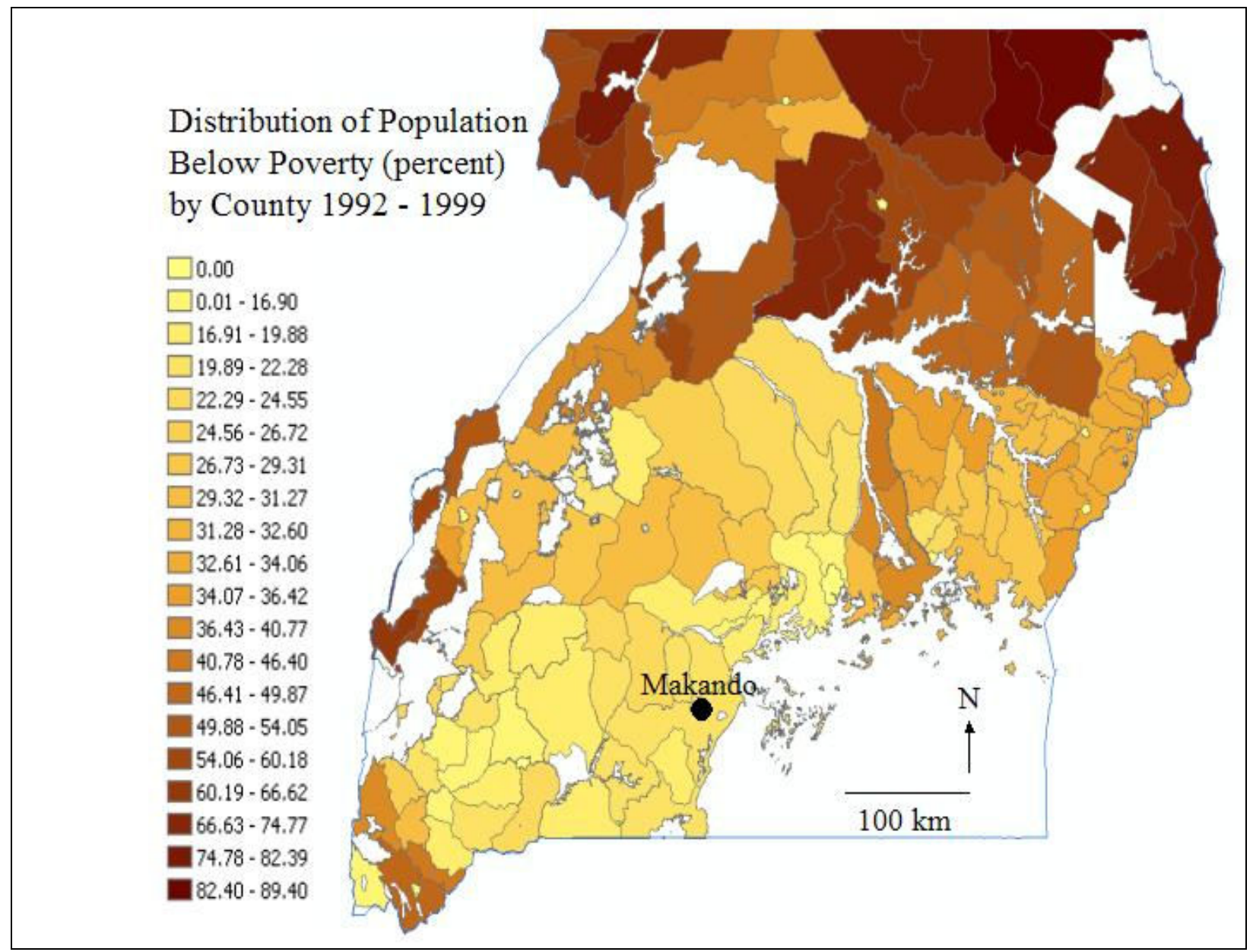

Figure 4. This example ArcGIS mapping was created by one of the freshmen water facility teams, and illustrates the percent of the population living below the poverty line for each county in Uganda. 


\section{Conclusions}

The two NSF Scholarship projects, the curriculum development project and the water facility design, are on schedule. The attainment of the first year goals, which include the completion of the curriculum and the ArcGIS maps, is expected to be achieved by the conclusion of the spring semester. During the spring semester, lesson plans and laboratory experiments will be developed and uploaded to the internet for distribution at St. Denis, and instructional posters will be created and mailed to Uganda. Likewise, the finalized ArcGIS maps will be distributed for use to Into Your Hands engineers and mailed to St. Denis for educational purposes.

After one semester into the program, scholarship recipients are performing well academically, as evident by their high grade point averages summarized in Table 1 . None of the scholarship recipients chose to leave the school or the program after their first semester. This is a positive result given that Colorado School of Mines has an $83 \%$ first semester retention rate. As reported in Table 2, the scholarship recipients dedicated more than the minimum time requirement to their projects, indicating their interest and excitement with regard to this effort. Further support for this interpretation is provided by their positive responses to the focus group activity. Many of the freshman commented on the importance of the relationships that they had established as part of this project with their peers, the graduate students and the faculty.

Another milestone for the spring semester is the selection of projects for the next academic year. Unlike the projects selected in the first year, the scholarship recipients will be active participants in the selection of international, national or local level projects. By providing recipients the autonomy to select projects, the investigators anticipate even greater enthusiasm and support from scholarship recipients in the second year. Regardless of the specific projects chosen for subsequent years, the NSF Scholarship Program is likely to create benefits for many levels of society, from retaining promising, need-based engineering students, to training future engineers about globally responsible engineering practices, to initiating constructive results in vulnerable communities.

\section{Acknowledgements}

This research is supported by the National Science Foundation Grant Number NSF, DUE-0630888 and is part of the on-going efforts of the Center for Assessment of Science, Technology, Engineering and Mathematics at the Colorado School of Mines (see http://www.mines.edu/research/ca-stem/).

\section{References}

1 Bellinger, R. and Leopold, G. (1998). Industry lauds H-1B vote; vows to aid U.S. education. EE Times.

2 United States Congress (2000). American Competitiveness in the Twenty-first Century Act of 2000. On-line: http://rpc.senate.gov/_files/L73IMjj091800.pdf. 
3 White House (2006). Fact Sheet: American Competitiveness Initiative: Encouraging Innovation. On-line: http://www.whitehouse.gov/news/releases.

4 Downey, G., Lucena, J., Moskal, B., Parkhurst, R., Bigley, T., Hays C., Jesiek, B., Kelly, L., Miller, J., and Ruff, S. The Globally Competent Engineer: Working Effectively with People Who Define Problems Differently, Journal of Engineering Education, 95 (2), 107-122 (2006).

5 Accreditation Board for Engineering and Technology, Criteria for Accrediting Engineering Programs, On-line: http://www.abet.org/Linked\%20DocumentsUPDATE/Criteria\%20and\%20PP/E001\%200708\%20EAC\%20Criteria $\%$ 2011-15-06.pdf (2006).

6 National Academies of Engineering, The Engineer of 2020: Visions of Engineering in the New Century, National Academies Press: Washington, DC, U.S.A. (2004).

7 Moskal, B., Skokan, C., Munoz D., and Goskink J. (in press) "Humanitarian engineering: Global impacts and sustainability of a curricular effort." International Journal of Engineering Education.

8 Moskal, B., Skokan, S., Dean, A., Kosbar, A., Westland, C., Barker, H., Nguyen, N., and Tafoya, J. K-12 Outreach: Identifying the Broader Impacts of Four Outreach Projects, Journal of Engineering Education (in press).

9 Into Your Hands (2008). Mission of Into Your Hands. On-line: A http://intoyourhands.org.

10 Educate Africa (2008). The Educational System in Uganda, Africa. On-line: http://www.educateafrica.org/ AboutUs/educationsystem.htm.

11 Moskal, B. and Skokan, C. (2004). "GK-12 Learning Partnerships: An outreach program in engineering education." Presentation at International Conference to Review Research in Science, Technology and Mathematics Education, Goa, India.

12 Moskal, B., Skokan C., and Duffield, J. (Oct. 2004). "GK-12 Learning Partnerships: An outreach program in engineering education". Proceedings of the International Conference on Engineering Education, Gainesville, Florida.

13 Munoz, D., Bratrsovsky, A., Cognets, R., McClure, K., Uhlemann, G., and Wolfram, P. (2007). "Water for Uganda." Senior Design Course Semester Presentation.

14 Retention Rates 2004 - 2005, Colorado Department of Higher Education: Division of Information and Research Management.

15 Colorado School of Mines: Student Enrollment, Transfer, Retention and Graduation Rate, 2003. On-line: http:// 209.85.173.104/search?q=cashe:saP1pydaZRcJ:www.state.co.us/cche/agenda

16 Uganda Governmental Mandated Education, Chapter V: Science Subjects, “500 General Science.” p 120 - 191.

17 DEPHA, http://www.depha.org/maps/uganda/default.asp, website access December 15, 2007.

18 IGAD LPI Online Data Portal, http://ergodd.zoo.ox.ac.uk/igadweb/tiki-index.php?page= Uganda+Data, website access December 15, 2007. 